\title{
Effects of Inclusion of $N$-Carbamylglutamate in the Non-Protein Diet on Growth and Slaughter Performance, Meat Quality, Nitrogen Metabolism and Antioxidant of Holstein Bulls
}

\author{
Quanyu Zhang, Guangning Zhang, Xinyue Zhang, Jinshan Yang and Yonggen Zhang * \\ College of Animal Science and Technology, Northeast Agricultural University, Harbin 150030, China; \\ yugezuishuai1314@yeah.net (Q.Z.); zhangguangning@neau.edu.cn (G.Z.); 18846910512@163.com (X.Z.); \\ yjs853396960@sina.com (J.Y.) \\ * Correspondence: zhangyonggen@sina.com
}

check for

updates

Citation: Zhang, Q.; Zhang, G.;

Zhang, X.; Yang, J.; Zhang, Y. Effects of Inclusion of $\mathrm{N}$-Carbamylglutamate in the Non-Protein Diet on Growth and Slaughter Performance, Meat Quality, Nitrogen Metabolism and Antioxidant of Holstein Bulls. Animals 2022, 12, 33. https:// doi.org/10.3390/ani12010033

Academic Editor: Susana Alves

Received: 10 November 2021

Accepted: 16 December 2021

Published: 24 December 2021

Publisher's Note: MDPI stays neutral with regard to jurisdictional claims in published maps and institutional affiliations.

Copyright: (C) 2021 by the authors. Licensee MDPI, Basel, Switzerland. This article is an open access article distributed under the terms and conditions of the Creative Commons Attribution (CC BY) license (https:// creativecommons.org/licenses/by/ $4.0 /$ )
Simple Summary: Using dietary non-protein nitrogen is an effective way to decrease the dependence on protein resources in cattle production. $N$-carbamylglutamate (NCG) is a structural analogue of $\mathrm{N}$-acetylglutamate (NAG), which is a precursor of endogenous Arg synthesis. NCG improves urea cycling and enhances the endogenous synthesis of Arg, nitric oxide synthase and NO. The present study showed that beef benefited from being fed NCG product in the urea diet by enhancing its growth and slaughter performance, meat quality, nitrogen metabolism and plasma amino acids.

\begin{abstract}
The objectives of this experiment were to investigate the effects of $N$-carbamylglutamate (NCG) on growth and slaughter performance, meat quality, nitrogen utilization, plasma antioxidant and amino acids of Holstein bulls. In this case, 24 Holstein bulls ( $490 \pm 29.0 \mathrm{~kg}$ of body weights and $540 \pm 6.1 \mathrm{~d}$ of age) were blocked by body weights and age and randomly assigned to 1 of 4 groups: (1) CON group: bulls were fed the control diet, (2) CON + NCG group: bulls were fed the control diet with $40 \mathrm{mg} / \mathrm{kg}$ BW NCG, (3) Urea group: bulls were fed the urea diet, and (4) Urea + NCG group: bulls were fed the urea diet with $40 \mathrm{mg} / \mathrm{kg}$ BW NCG. Feeding NCG significantly improved ADG, FCR, DM and CP digestibility, carcass weight, slaughter weight, DOP, eye muscle area, shear force $(p=0.001)$ and reduced $L^{*}$ of color, drip loss and cooking loss. Concurrently, feeding the urea diet induced a decreased ADG, carcass weight and slaughter weight, DOP, eye muscle area and shear force. NCG decreased contents of fecal N and urinary N, plasma urea in bulls and ammonia but increased $\mathrm{N}$ retention and utilization, plasma NO, plasma Arg, Leu, Ile and Tyr. On the other hand, feeding the urea diet increased urinary $\mathrm{N}$, plasma urea and ammonia. Thus the study efficiently demonstrates that beef benefited from being fed a NCG product in the urea diet by enhancing its growth and slaughter performance, meat quality, nitrogen metabolism and plasma amino acids.
\end{abstract}

Keywords: Holstein bulls; $N$-carbamylglutamate; meat quality; nitrogen metabolism

\section{Introduction}

Due to the economic and environmental considerations, the improvement of $\mathrm{N}$ utilization and production performance of cattle are of interest. The shortage of protein feed resources and excessive nitrogen excretion restricts the development of animal husbandry around the world. Using dietary non-protein nitrogen is an effective way to decrease the dependence on protein resources in cattle production. Ruminants can convert non-protein nitrogen to digestible microbial protein by rumen microbes. However, little information is available on the impact of non-protein nitrogen on slaughter performance, meat quality and nitrogen metabolism in Holstein bulls.

Arginine (Arg) is a functional essential amino acid and participates in the synthesis of urea, polyamines and nitric oxide (NO) [1]. Furthermore, dietary Arg enhanced bowel mucosal function in newborn and weaned pigs and improved antioxidant and immune function in rats [2,3]. However, rumen-protected and exogenous arginine impaired the 
absorption of alkaline amino acids and appeared to be uneconomical [4]. Thus, promoting endogenous synthesis of Arg to enhance the supply of Arg is an effective and economical strategy. $N$-carbamylglutamate (NCG) is a structural analogue of $N$-acetylglutamate (NAG), which is a precursor of endogenous Arg synthesis [5]. NCG improves urea cycling and enhances the endogenous synthesis of Arg, nitric oxide synthase and NO [6]. Recent findings demonstrated improvements in protein synthesis in skeletal muscle and mTOR signaling activity in pigs supplemented with NCG [5,7]. The increases in the milk protein yield may be related to a balanced amino acids profile, plasma $\mathrm{NO}$ and ammonia by promoting ureagenesis [6]. Intrauterine growth restriction in suckling lambs could be mitigated by supplying Arg and NCG through a nitric oxide-dependent pathway [8]. Dietary NCG was proved to promote energy metabolism for the damaged intestine by increasing ATP levels in the intestine of rats [9].

However, the impacts of supplementation of NCG in the urea diet on meat quality and nitrogen metabolism of Holstein bulls have rarely been studied. Although urea diets can reduce costs, low nitrogen utilization leads to environmental pollution. Therefore, the objectives of the present experiment were to explore the effects of inclusion of NCG in the basal or urea diet on growth performance of the fatting period and slaughter performance (slaughter weight, carcass weight, DOP), meat quality, nitrogen utilization, plasma antioxidant and amino acids of bulls.

\section{Materials and Methods}

\subsection{Animals, Experimental Design and Diets}

This study was performed at the Acheng Test Base of Northeast Agricultural University (Harbin, China) from April 2019 to June 2019. The experimental animal procedures recommended by the Animal Care and Use Committee (Protocol number: NEAU-[2011]-9) were approved by Northeast Agricultural University. In this case, 24 Holstein bulls (body weights; BW, $490 \pm 29.0 \mathrm{~kg}$ and ages $540 \pm 6.1 \mathrm{~d}$ ) were used to conduct a completely randomized block design. After 2 weeks of adaptation, bulls were randomly assigned to 1 of 4 treatments according to BW and age: (1) CON group: bulls were fed the control diet, (2) CON + NCG group: bulls were fed the control diet with $40 \mathrm{mg} / \mathrm{kg}$ BW NCG, (3) Urea group: bulls were fed the urea diet, and (4) Urea + NCG group: bulls were fed the urea diet with $40 \mathrm{mg} / \mathrm{kg}$ BW NCG. Bulls were housed in individual pens $\left(2.5 \times 3 \mathrm{~m}^{2}\right)$ on floor bedding with a front metal gate allowing access to feed and water.

The isoenergetic diets were formulated to nutrient requirements of bulls according to recommendations of the Beef Cattle Nutrient Requirements Model (2016), and ingredients and nutrient compositions are shown in Table 1. The NCG used in the current study (purity $\geq 97 \%$ ) was obtained from ANIMORE SCI and TECH (Beijing) Co., Ltd. (Beijing, China). A top-dress supplement for each treatment was prepared by mixing $40 \mathrm{mg} / \mathrm{kg}$ BW NCG with $500 \mathrm{~g}$ diets, the top-dress was not mixed into the ration and was consumed readily by all cows, and the remanent was fed subsequently at 6 a.m. every day. Bulls were fed twice per day at 6 a.m. and 6 p.m. during a 7 week period. The orts of each bull were collected every morning. The offered feed was adjusted for at least $5 \%$ refusal daily according to intake of the day before. 
Table 1. Ingredient and chemical composition of the basal diets (dry matter basis).

\begin{tabular}{ccc}
\hline Parameter & The CON Diet \% & The Urea Diet \% \\
\hline Ingredient composition, \% of DM & & \\
Corn grain & 46 & 51 \\
Soybean meal & 5 & - \\
Urea & - & 1 \\
Peanut hull & 15 & 15 \\
Soybean skin & 10 & 10 \\
Corn gluten feed & 11 & 10 \\
Corn germ meal & 5 & 5 \\
Molasses & 5 & 5 \\
Salt & 0.8 & 0.8 \\
Limestone & 1 & 1 \\
Magnesium oxide & 0.5 & 0.5 \\
Sodium bicarbonate & 0.5 & 0.5 \\
Mineral-vitamin premix 1 & 0.2 & 0.2 \\
Chemical composition, $\%$ of DM & & \\
OM & 92.6 & 93.2 \\
CP & 12.8 & 13.5 \\
NDF & 34.4 & 34.3 \\
ADF & 18.2 & 18.2 \\
EE & 3.3 & 3.2 \\
Ca & 0.8 & 0.8 \\
P & 0.4 & 0.4 \\
ME (MJ/kg) & 11.4 & 11.5 \\
\hline
\end{tabular}

${ }^{1}$ The premix provided the following per kilogram of the diet: VA $2500 \mathrm{IU}, \mathrm{VD} 500 \mathrm{IU}, \mathrm{VE} 10 \mathrm{IU}, \mathrm{Fe} 10 \mathrm{mg}$, Cu $15.0 \mathrm{mg}$, Mn $20 \mathrm{mg}$, Zn $25 \mathrm{mg}$, I $0.50 \mathrm{mg}$, Co $0.10 \mathrm{mg}$. The percentage of minerals in the premix was $28.3 \%$; the percentage of vitamins in the premix was $2.60 \%$.

\subsection{Sample Collection}

Body weights were recorded on the 0, 4 and 7 weeks of the experiment. Dry matter intake (DMI) was recorded daily by weighting feed offered and refused for individual bulls. Growth performance was evaluated by calculating the average daily gain (ADG) and feed conversion ratio (FCR). Samples of feed, orts, and diets were taken weekly and stored at $-20^{\circ} \mathrm{C}$. Approximately $500 \mathrm{~g}$ of fecal samples per bull were taken from the rectum at 6 a.m. and 6 p.m. on the last three days of 0,4 and 7 weeks. All the samples were dried at $55^{\circ} \mathrm{C}$ for $48 \mathrm{~h}$, ground to pass through a 1-mm screen in a Wiley mill. Urine was sampled by stimulation at 6 a.m. and 6 p.m. on the last three days of weeks 0,4 and 7, and then acidified by $\mathrm{H}_{2} \mathrm{SO}_{4}$ and stored at $-20^{\circ} \mathrm{C}$ until analysis. Urine volume was estimated by measuring creatinine as a marker $[10,11]$. In calculating urine volume, we assumed creatinine output averages $29 \mathrm{mg} / \mathrm{kg}$ of BW as estimated [12]. Creatinine was detected by a colorimetric picric acid method [13]. Blood was collected from coccygeal vein by sodium heparin tubes $3 \mathrm{~h}$ after the morning feeding at 0,4 and 7 weeks, and then centrifuged at $2000 \times g$ for 15 min at $4{ }^{\circ} \mathrm{C}$ to obtain plasma and stored at $-20{ }^{\circ} \mathrm{C}$ until analysis.

\subsection{Analysis of Nutrient Digestibility and Nitrogen Metabolism}

The samples of feed and feces were examined for nutritional composition. The dry matter (DM, method 934.01), crude protein (CP, method 954.01), and ether extract (EE, method 920.39) were analyzed following the methods of AOAC International (2000) [14]. The neutral detergent fiber (NDF) was measured using a heat stable $\alpha$-amylase [15]. The total tract apparent nutrient digestibility was estimated by quantifying the concentrations of indigestible NDF (iNDF) as an internal marker in the feed and feces [16]. The iNDF in the feces, feed and orts were determined by a $288 \mathrm{~h}$ in situ incubation [17]. Fecal N (g/d) $=[\mathrm{CP}$ intake $(\mathrm{g} / \mathrm{d})-\mathrm{CP}$ intake $(\mathrm{g} / \mathrm{d}) \times \%$ of CP Digestibility $] /(\%$ of $\mathrm{CP}$ in feces $) / 6.25$; urine $\mathrm{N}(\mathrm{g} / \mathrm{d})=$ urine volume $(\mathrm{L} / \mathrm{d}) \times[\mathrm{CP}$ in urine $(\mathrm{g} / \mathrm{L})] / 6.2512$. Nitrogen retention was calculated as $\mathrm{N}$ retention $(\mathrm{g} / \mathrm{d})=\mathrm{N}$ intake - fecal $\mathrm{N}-$ urine $\mathrm{N}$. Nitrogen utilization = $(\mathrm{N}$ retention $/ \mathrm{N}$ intake $) \times 100$. 


\subsection{Analysis of Plasma Antioxidant Capacity and Amino Acids}

Bovine plasma urea and ammonia were analyzed using two-point dynamic method by a fully automatic biochemical analyzer (HT82-BTS-330, Xihuayi Technology Co., Ltd., Beijing, China). Plasma antioxidant capacity was measured with commercial kits (Nanjing Jiancheng Institute of Bioengineering, Nanjing, China). Plasma nitric oxide (NO), total antioxidant capacity (T-AOC), catalase (CAT), total superoxide dismutase (T-SOD), glutathione (GSH) were analyzed using the nitrate reductase, 2, 2' -azino-bis(3-ethylbenzothiazoline6-sulfonic acid, visible light, hydroxylamine, thiobar-bituric and colorimetric methods following the kit structures. Plasma amino acids were analyzed by HPLC-coupled with MS detection (HPLC-LCMS/MS API3200 Q-TRAP, Thermo Fisher Scientific, Waltham, MA, USA).

\subsection{Slaughter Performance and Meat Quality}

Live weights just before slaughter were determined. At slaughter, they were stunned by captive bolt, exsanguinated and dressed. Carcass weights were determined after splitting of the carcass. The carcasses were chilled for $24 \mathrm{~h}$ in a room with temperature $0^{\circ} \mathrm{C}$. Dressing out percentage (DOP) was measured by the cold carcass weight divided by the live weight and then multiplied by 100. The weight of the liver, spleen and kidney were used to calculate the organ index. Meat $\mathrm{pH}$ and color value were measured at three spots on the longissimus dorsi. The $\mathrm{pH}$ value was measured using a $\mathrm{pH}$ meter (PHS-3C; Nanjing Nanda Analytical Instrument Application Research Institute, Nanjing, China). The meat color ( $\mathrm{L}^{*}$, brightness; $\mathrm{a}^{*}$, redness and $\mathrm{b}^{*}$, yellowness) was determined using a Minolta device. The eye muscle $\left(\mathrm{cm}^{2}\right)$ was calculated according to the cross-sectional area of longissimus dorsi between the 12th and 13th ribs. The meat was pre-weighed into a polystyrene tray with a driloc pad, over-wrapped with oxygen permeable film, and stored for $5 \mathrm{~d}$ at $1{ }^{\circ} \mathrm{C}$ for determination of drip loss. Cooking loss was carried out by cooking the slices in a water bath at $75{ }^{\circ} \mathrm{C}$ for $50 \mathrm{~min}$. The $12.7 \mathrm{~mm}$ cores were sampled from the meat and sheared transversely with a Warner-Bratzler shear blade fitted to a Model 6021 Instron Universal Testing Instrument (Instron, High Wycombe, Bucking-hamshire, UK).

\subsection{Statistical Analysis}

Normality of the data was examined for normal distribution using Minitab [17] (Minitab, Inc., State College, PA, USA, 2014). All data were analyzed according to the Mixed procedure of SAS 9.4 (SAS Institute, Cary, NC, USA), included the diet (CON vs. Urea), NCG supplementation (0 vs. $40 \mathrm{mg} / \mathrm{kg}$ ), diet $\times$ NCG and time were considered as fixed effects and the random effect of bull. Initial variables were used as covariates for analyses. Data were reported as least squares means and statistical significance was considered at $p \leq 0.05$, and a tendency was considered at $0.05<p \leq 0.10$. When an interaction between diet and NCG was significant, differences among the factors were analyzed by the SLICE option of LSMEANS statement.

\section{Results}

\subsection{Growth Performance and Digestibility of Nutrients}

The lower ADG $(p<0.01)$ in bulls supplemented with urea diet was observed compared to those supplemented with control diet, but supplementing NCG increased ADG of bulls fed the urea diet $(p<0.01)$. In addition, feeding NCG significantly improved ADG $(p<0.01)$ and FCR $(p=0.02)$ compared to without feeding NCG (Table 2$)$. Digestibility of $\mathrm{DM}(p=0.01)$ and CP $(p=0.02)$ were significantly higher in bulls fed NCG than those fed without NCG. 
Table 2. Effects of supplementation with N-carbamylglutamate (NCG) in urea diet on the growth performance in Holstein bulls.

\begin{tabular}{|c|c|c|c|c|c|c|c|c|}
\hline \multirow{2}{*}{ Parameter } & \multicolumn{4}{|c|}{ Treatment $^{1}$} & \multirow{2}{*}{ SEM } & \multicolumn{3}{|c|}{$p$-Values } \\
\hline & $\mathrm{CON}$ & $\mathrm{CON}+\mathrm{NCG}$ & Urea & Urea + NCG & & Basal Diet & NCG & Basal Diet $\times$ NCG \\
\hline \multicolumn{9}{|c|}{ Growth Performance } \\
\hline $\mathrm{ADG}, \mathrm{kg} / \mathrm{d}$ & 1.48 & 1.74 & 1.32 & 1.71 & 0.11 & $<0.01$ & $<0.01$ & $<0.01$ \\
\hline FCR & 8.40 & 6.91 & 8.48 & 7.33 & 0.68 & 0.45 & 0.02 & 0.15 \\
\hline \multicolumn{9}{|c|}{ Intake, $\mathrm{kg} / \mathrm{d}$} \\
\hline $\mathrm{DM}$ & 12.4 & 12.0 & 11.7 & 12.5 & 0.83 & 0.43 & 0.36 & 0.17 \\
\hline $\mathrm{CP}$ & 1.56 & 1.49 & 1.57 & 1.56 & 0.07 & 0.31 & 0.24 & 0.08 \\
\hline NDF & 4.26 & 4.16 & 4.01 & 4.29 & 0.18 & 0.32 & 0.25 & 0.13 \\
\hline $\mathrm{ADF}$ & 2.26 & 2.20 & 2.13 & 2.28 & 0.09 & 0.31 & 0.24 & 0.22 \\
\hline \multicolumn{9}{|c|}{ Digestibility \% } \\
\hline DM & 66.9 & 68.7 & 66.6 & 68.6 & 0.68 & 0.78 & 0.01 & 0.88 \\
\hline $\mathrm{CP}$ & 71.2 & 74.4 & 69.6 & 72.7 & 1.30 & 0.21 & 0.02 & 0.99 \\
\hline NDF & 34.5 & 36.8 & 35.1 & 38.1 & 1.38 & 0.49 & 0.06 & 0.79 \\
\hline $\mathrm{ADF}$ & 27.0 & 27.9 & 27.2 & 31.3 & 2.55 & 0.27 & 0.13 & 0.34 \\
\hline
\end{tabular}

Note: ${ }^{1}$ ADG, average daily gain; FCR, feed conversion ratio (kg of DMI/kg of ADG); DM, dry matter; CP, crude protein; NDF, neutral detergent fiber; $\mathrm{ADF}$, acid detergent fiber. $\mathrm{CON}$ : feeding basic diet; $\mathrm{CON}+\mathrm{NCG}$ feeding basic diet supplemented with $40 \mathrm{mg} / \mathrm{kg}$ BW NCG daily; Urea: feeding with urea as nitrogen source diets; Urea + NCG: feeding with urea as nitrogen source diets supplemented with $40 \mathrm{mg} / \mathrm{kg}$ BW NCG daily.

\subsection{N Metabolism}

Supplementing bulls with NCG significantly decreased fecal N ( $p=0.02$; Table 3). The urinary $\mathrm{N}$ significantly increased $(p=0.02)$ in bulls fed the urea diet, nevertheless, feeding NCG significantly decreased the urinary N $(p=0.02)$ in bulls. The $\mathrm{N}$ retention $(p=0.01)$ and N utilization $(p=0.003)$ significantly increased in bulls fed NCG.

Table 3. Effects of supplementation with $N$-carbamylglutamate (NCG) in urea diet on $\mathrm{N}$ metabolism in Holstein bulls.

\begin{tabular}{|c|c|c|c|c|c|c|c|c|}
\hline \multirow{2}{*}{ Parameter } & \multicolumn{4}{|c|}{ Treatment $^{1}$} & \multirow{2}{*}{ SEM } & \multicolumn{3}{|c|}{$p$-Values } \\
\hline & $\mathrm{CON}$ & $\mathrm{CON}+\mathrm{NCG}$ & Urea & Urea + NCG & & Basal Diet & NCG & Basal Diet $\times$ NCG \\
\hline & & & & N Metabolism, $\mathrm{g} / \mathrm{d}$ & & & & \\
\hline $\mathrm{N}$ intake & 249 & 238 & 251 & 250 & 4.86 & 0.15 & 0.24 & 0.29 \\
\hline Fecal N & 82.2 & 69.9 & 80.5 & 69.9 & 4.55 & 0.85 & 0.02 & 0.86 \\
\hline Urinary N & 105 & 95.2 & 121 & 105 & 5.16 & 0.02 & 0.02 & 0.57 \\
\hline $\mathrm{N}$ retention & 62.2 & 73.3 & 50.1 & 75.8 & 7.07 & 0.50 & 0.01 & 0.31 \\
\hline $\begin{array}{c}\mathrm{N} \\
\text { utilization }\end{array}$ & 0.24 & 0.31 & 0.20 & 0.30 & 0.03 & 0.39 & 0.003 & 0.40 \\
\hline
\end{tabular}

Note: ${ }^{1}$ CON: feeding basic diet; CON + NCG: feeding basic diet supplemented with $40 \mathrm{mg} / \mathrm{kg}$ BW NCG daily; Urea: feeding with urea as nitrogen source diets; Urea + NCG: feeding with urea as nitrogen source diets supplemented with $40 \mathrm{mg} / \mathrm{kg}$ BW NCG daily.

\subsection{Plasma Biochemistry and Antioxidants Index}

The plasma urea significantly increased in bulls fed the urea diet $(p=0.02$; Table 4$)$, however, feeding NCG tended to decrease plasma urea in bulls $(p=0.09)$. Plasma ammonia increased $(p=0.04)$ when supplementing the urea diet, but the opposite response was observed $(p=0.02)$ in bulls fed NCG. The NO concentration in plasma tended $(p=0.09)$ to increase with feeding NCG. 
Table 4. Effects of supplementation with N-carbamylglutamate (NCG) in urea diet on the plasma biochemistry and antioxidants index in Holstein bulls.

\begin{tabular}{|c|c|c|c|c|c|c|c|c|}
\hline \multirow{2}{*}{ Parameter } & \multicolumn{4}{|c|}{ Treatment $^{1}$} & \multirow{2}{*}{ SEM } & \multicolumn{3}{|c|}{$p$-Values } \\
\hline & $\mathrm{CON}$ & $\mathrm{CON}+\mathrm{NCG}$ & Urea & Urea + NCG & & Basal Diet & NCG & Basal Diet $\times$ NCG \\
\hline Urea, $\mathrm{mmol} / \mathrm{L}$ & 3.52 & 3.14 & 4.06 & 3.78 & 0.19 & 0.01 & 0.09 & 0.80 \\
\hline $\begin{array}{c}\text { Plasma ammonia, } \\
\mu \mathrm{mol} / \mathrm{L}\end{array}$ & 55.1 & 45.5 & 65.4 & 53.7 & 4.33 & 0.04 & 0.02 & 0.81 \\
\hline $\mathrm{NO}, \mu \mathrm{mol} / \mathrm{L}$ & 41.6 & 46.6 & 37.4 & 43.8 & 3.28 & 0.29 & 0.09 & 0.88 \\
\hline $\mathrm{T}-\mathrm{AOC}, \mathrm{U} / \mathrm{mL}$ & 8.98 & 9.01 & 8.89 & 9.03 & 0.72 & 0.96 & 0.91 & 0.94 \\
\hline CAT, U/mL & 69.1 & 66.3 & 66.6 & 65.1 & 2.50 & 0.46 & 0.39 & 0.80 \\
\hline T-SOD, U/mL & 74.4 & 76.7 & 78.9 & 73.8 & 3.07 & 0.80 & 0.65 & 0.23 \\
\hline $\mathrm{MDA}, \mathrm{nmol} / \mathrm{mL}$ & 3.92 & 3.79 & 3.86 & 3.87 & 0.09 & 0.89 & 0.52 & 0.47 \\
\hline $\mathrm{GSH}, \mu \mathrm{mol} / \mathrm{L}$ & 8.07 & 7.44 & 7.65 & 7.66 & 0.21 & 0.64 & 0.14 & 0.13 \\
\hline
\end{tabular}

Note: ${ }^{1} \mathrm{NO}$, nitric oxide; T-AOC, total antioxidant capacity; CAT, catalase; T-SOD, total superoxide dismutase MDA, malondialdehyde; GSH, glutathione. CON: feeding basic diet; CON + NCG: feeding basic diet supplemented with $40 \mathrm{mg} / \mathrm{kg}$ BW NCG daily; Urea: feeding with urea as nitrogen source diets; Urea + NCG: feeding with urea as nitrogen source diets supplemented with $40 \mathrm{mg} / \mathrm{kg}$ BW NCG daily.

\subsection{Plasma Amino Acids}

Regardless of urea supplementation in diets groups, bulls fed NCG had greater plasma $\operatorname{Arg}(p=0.04)$, Leu $(p=0.01)$, Ile $(p=0.01)$ and Tyr $(p=0.01)$ than those without supplementing NCG (Table 5). An interaction $(p=0.01)$ between the urea diet and NCG was observed for content of plasma Phe. Supplementing NCG increased plasma Phe of bulls fed without urea, but the opposite response was observed when bulls were fed the urea diet. Supplementation of NCG tended to improve plasma Val $(p=0.07)$.

Table 5. Effects of supplementation with $N$-carbamylglutamate (NCG) in urea diet on the plasma amino acids in Holstein bulls.

\begin{tabular}{|c|c|c|c|c|c|c|c|c|}
\hline \multirow{2}{*}{ Parameter } & \multicolumn{4}{|c|}{ Treatment $^{1}$} & \multirow{2}{*}{ SEM } & \multicolumn{3}{|c|}{$p$-Values } \\
\hline & CON & $\mathrm{CON}+\mathrm{NCG}$ & Urea & Urea + NCG & & Basal Diet & NCG & Basal Diet $\times$ NCG \\
\hline \multicolumn{9}{|c|}{$\mathrm{EAA}, \mu \mathrm{mol} / \mathrm{L}$} \\
\hline Arg & 159 & 193 & 143 & 167 & 12.7 & 0.12 & 0.04 & 0.69 \\
\hline His & 85.0 & 83.4 & 85.2 & 89.3 & 5.80 & 0.61 & 0.83 & 0.63 \\
\hline Leu & 132 & 158 & 132 & 150 & 8.31 & 0.63 & 0.01 & 0.64 \\
\hline Ile & 92.0 & 104 & 83.5 & 102 & 5.24 & 0.35 & 0.01 & 0.52 \\
\hline Lys & 165 & 167 & 136 & 139 & 18.8 & 0.15 & 0.92 & 0.98 \\
\hline Met & 31.9 & 31.0 & 33.3 & 33.3 & 2.20 & 0.40 & 0.84 & 0.84 \\
\hline Phe & 40.0 & 47.9 & 46.5 & 37.7 & 2.71 & 0.51 & 0.88 & 0.01 \\
\hline Thr & 59.2 & 73.0 & 73.1 & 67.4 & 10.3 & 0.69 & 0.69 & 0.36 \\
\hline Val & 210 & 236 & 200 & 227 & 13.8 & 0.50 & 0.07 & 0.99 \\
\hline TEAA & 974 & 1092 & 933 & 1012 & 69.8 & 0.39 & 0.17 & 0.78 \\
\hline \multicolumn{9}{|c|}{$\mathrm{NEAA}, \mu \mathrm{mol} / \mathrm{L}$} \\
\hline Ala & 255 & 236 & 237 & 230 & 9.16 & 0.21 & 0.18 & 0.53 \\
\hline Glu & 114 & 108 & 116 & 103 & 7.26 & 0.82 & 0.20 & 0.63 \\
\hline Pro & 82.8 & 81.2 & 76.9 & 81.1 & 4.49 & 0.52 & 0.78 & 0.52 \\
\hline Gly & 362 & 381 & 377 & 413 & 17.9 & 0.21 & 0.13 & 0.65 \\
\hline Ser & 95.9 & 94.3 & 91.2 & 95.3 & 5.42 & 0.74 & 0.82 & 0.61 \\
\hline Tyr & 53.7 & 67.5 & 47.7 & 61.1 & 4.44 & 0.18 & 0.01 & 0.97 \\
\hline Cys & 0.180 & 0.130 & 0.181 & 0.155 & 0.11 & 0.90 & 0.21 & 0.91 \\
\hline Asp & 18.1 & 18.1 & 14.8 & 19.3 & 1.38 & 0.44 & 0.13 & 0.12 \\
\hline TNEAA & 981 & 987 & 961 & 1003 & 29.4 & 0.94 & 0.43 & 0.54 \\
\hline
\end{tabular}

Note: ${ }^{1}$ EAA, essential amino acid; TEAA, total essential amino acid; NEAA, nonessential amino acid; TNEAA total nonessential amino acid; Arg, arginine; His, Histidine; Leu, Leucine; Ile, Isoleucine; Lys, Lysine; Met, Methionine; Phe, Phenylalanine; Thr, Threonine; Val, Valine; Ala, Alanine; Glu, Glutamic acid; Pro, Proline; Gly, Glycine; Ser, Serine; Tyr, Threonine; Cys, Cysteine; Asp, Aspartic. CON: feeding basic diet; CON + NCG: feeding basic diet supplemented with $40 \mathrm{mg} / \mathrm{kg}$ BW NCG daily; Urea: feeding with urea as nitrogen source diets, Urea + NCG: feeding with urea as nitrogen source diets supplemented with $40 \mathrm{mg} / \mathrm{kg}$ BW NCG daily. 


\subsection{Slaughter Performance and Organ Index}

Feeding a diet with NCG increased carcass weight $(p=0.02$; Table 6$)$. Bulls fed the urea diet had lower carcass weight $(p=0.02)$ and slaughter weight $(p=0.06)$ than those fed the control diet. Supplementing bulls with urea diet decreased DOP $(p=0.02)$, but feeding diet with NCG tended to enhance DOP of bulls $(p=0.08)$. No difference $(p>0.1)$ was present between treatments on organ index.

Table 6. Effects of supplementation with N-carbamylglutamate (NCG) in urea diet on the slaughter performance and organ index in Holstein bulls.

\begin{tabular}{|c|c|c|c|c|c|c|c|c|}
\hline \multirow{2}{*}{ Parameter } & \multicolumn{4}{|c|}{ Treatment ${ }^{1}$} & \multirow{2}{*}{ SEM } & \multicolumn{3}{|c|}{$p$-Values } \\
\hline & CON & $\mathrm{CON}+\mathrm{NCG}$ & Urea & Urea + NCG & & Basal Diet & NCG & Basal Diet $\times$ NCG \\
\hline $\begin{array}{l}\text { Slaughter weight } \\
(\mathrm{kg})\end{array}$ & 645 & 657 & 613 & 613 & 9.29 & 0.06 & 0.90 & 0.13 \\
\hline Carcass weight $(\mathrm{kg})$ & 357 & 381 & 336 & 347 & 10.8 & 0.05 & 0.02 & 0.19 \\
\hline DOP $(\%)$ & 55.3 & 57.9 & 54.8 & 56.7 & 0.29 & 0.02 & 0.08 & 0.33 \\
\hline Organ index \% & & & & & & & & \\
\hline Liver index \% & 1.42 & 1.45 & 1.47 & 1.39 & 0.07 & 0.73 & 0.44 & 0.66 \\
\hline Spleen index \% & 0.22 & 0.21 & 0.21 & 0.22 & 0.01 & 0.39 & 0.69 & 0.71 \\
\hline Kidney index \% & 0.25 & 0.27 & 0.26 & 0.27 & 0.02 & 0.30 & 0.73 & 0.86 \\
\hline
\end{tabular}

Note: ${ }^{1}$ CON: feeding basic diet; CON + NCG: feeding basic diet supplemented with $40 \mathrm{mg} / \mathrm{kg}$ BW NCG daily; Urea: feeding with urea as nitrogen source diets; Urea + NCG: feeding with urea as nitrogen source diets supplemented with $40 \mathrm{mg} / \mathrm{kg}$ BW NCG daily.

\subsection{Meat Quality}

Eye muscle area in bulls fed the urea diet was less than those fed the control diet $(p=0.001$; Table 7). Eye muscle area significantly increased in bulls fed NCG $(p=0.001)$. Feeding NCG significantly decreased drip loss $(p=0.001)$ and cooking loss $(p=0.001)$. Feeding NCG significantly increased shear force $(p=0.001)$. The $\mathrm{L}^{*}$ score tended to increase $(p=0.07)$ in bulls fed the urea diet, but the $L^{*}$ score significantly deceased $(p=0.03)$ in bulls fed NCG.

Table 7. Effects of supplementation with $N$-carbamylglutamate (NCG) in urea diet on the meat quality in Holstein bulls.

\begin{tabular}{|c|c|c|c|c|c|c|c|c|}
\hline \multirow{2}{*}{ Parameter } & \multicolumn{4}{|c|}{ Treatment $^{1}$} & \multirow{2}{*}{ SEM } & \multicolumn{3}{|c|}{$p$-Values } \\
\hline & CON & $\mathrm{CON}+\mathrm{NCG}$ & Urea & Urea + NCG & & Basal Diet & NCG & Basal Diet $\times$ NCG \\
\hline $\mathrm{pH}$ & 6.98 & 6.81 & 6.88 & 6.88 & 0.05 & 0.70 & 0.11 & 0.11 \\
\hline Eye muscle area $\mathrm{cm}^{2}$ & 80.3 & 82.5 & 77.9 & 79.8 & 0.26 & 0.001 & 0.001 & 0.66 \\
\hline Drip loss $\%$ & 4.75 & 3.52 & 4.47 & 3.09 & 0.27 & 0.23 & 0.001 & 0.79 \\
\hline \multicolumn{9}{|l|}{ Color } \\
\hline$L^{*}$ & 29.4 & 26.2 & 31.9 & 28.7 & 1.19 & 0.07 & 0.03 & 0.99 \\
\hline$a^{*}$ & 13.3 & 11.9 & 12.9 & 13.4 & 0.45 & 0.44 & 0.49 & 0.18 \\
\hline$b^{*}$ & 2.55 & 1.82 & 2.82 & 2.57 & 0.40 & 0.24 & 0.26 & 0.57 \\
\hline Cooking loss (\%) & 33.4 & 22.9 & 33.6 & 26.8 & 1.42 & 0.19 & 0.001 & 0.23 \\
\hline Shear force $\mathrm{N}$ & 70.7 & 78.9 & 57.1 & 78.2 & 3.02 & 0.04 & 0.001 & 0.07 \\
\hline
\end{tabular}

Note: ${ }^{1}$ CON: feeding basic diet; CON + NCG: feeding basic diet supplemented with $40 \mathrm{mg} / \mathrm{kg}$ BW NCG daily; Urea: feeding with urea as nitrogen source diets; Urea + NCG: feeding with urea as nitrogen source diets supplemented with $40 \mathrm{mg} / \mathrm{kg}$ BW NCG daily.

\section{Discussion}

\subsection{Growth, N Metabolism, Plasma Antioxidants and Amino Acids}

Consistent with previous studies, our results found that feeding the urea diet decreased ADG and DM and CP digestibility. The intake and growth performance of lambs were reduced by adding $8 \%$ urea to the diet [18]. Supplementing the urea diet instead of the protein feed to dairy cows also decreased milk yield [19]. This may be due to that urea 
can be rapidly hydrolyzed into ammonia-nitrogen in the rumen, however, rumen microbes have a low rate of synthesizing a microbial protein from ammonia-nitrogen, resulting in insufficient utilization of nitrogen in the urea diet. Supplementation of NCG induced changes in the nutrients digestibility. For instance, protein digestibility increased when bulls fed NCG. This could be explained by decreased fecal N. In addition, our study demonstrated that NCG enhanced ADG and subsequently improved FCR therefore, improving overall slaughter and carcass weight. Improved growth rate and muscle development by NCG treatment have been reported else in the literature [20]. In conclusion, the addition of NCG improved both the nitrogen utilization of the urea diet and consequently the ADG, while alleviating the difficult problem of protein feed shortage, which was supported by the synergistic effect between the urea diet and NCG. A previous study by our group suggested that supplementing Holstein bulls with $40 \mathrm{mg} / \mathrm{kg}$ of BW NCG was prior to increase growth performance compared with other doses [21]. Previous studies showed that dietary NCG had a beneficial effect on the feed efficiency of broilers and pigs [22,23]. NCG supplementation has a beneficial effect on nutrient digestion only if the dietary CP level is extremely lowered [24]. In addition, NCG improved the relative weight of the small intestine and intestinal morphology of pigs, which is beneficial for intestinal digestion 7. Arg has been recognized as a powerful factor stimulating insulin production [25]. Therefore, increased serum anabolic hormone level has been associated with greater nutrient partitioning toward processes involved in the synthesis of tissue proteins.

Feeding the urea diet increases ammonia concentrations and has been shown to decrease the efficiency of $\mathrm{N}$ utilization for milk and meat production. The addition of NCG decreased the urea N concentrations in plasma, milk, and urine, and resulted in a greater $\mathrm{N}$ conversion efficiency in dairy cows 6 . Arginine is a crucial AA related to the transportation, storage, and excretion of $\mathrm{N}$ and the disposition of ammonia via the urea cycle [26]. Thus, urea synthesis through NCG in ruminant gut tissues might improve N utilization. The higher concentrations of plasma urea and ammonia by feeding the urea diet suggested lower efficiency of $\mathrm{N}$ utilization because of the imbalance of amino acids for protein synthesis and accretion. Moreover, decreased plasma urea by feeding NCG suggested higher efficiency of net protein synthesis by promoting urea cycling [27]. Therefore, feeding NCG would have beneficial impacts on dietary $\mathrm{N}$ utilization and $\mathrm{N}$ digestibility. Similar to our result, a previous study found a reduced serum urea [20]. Feeding NCG reduced concentrations of plasma ammonia and urea in dairy cows 6 . Consistent with those studies, NCG decreased concentration of plasma ammonia, which suggested that NCG promoted ammonia reduction and Arg synthesis by accelerating urea recycling [28]. Arg is a crucial factor predominant in energy metabolism including fatty acids, glucose, and amino acids through nitric oxide production [29]. Feeding suckling lambs with Arg or NCG enhanced intestinal function by the operational antioxidant system by NO-signaling pathway 8. Arg can serve as a precursor of nitric oxide, creatine, ornithine, and polyamines. An increase in NO level affected the antioxidant capacity of the small bowel, thus modulating antioxidant defense [30]. Arg is a major component of the NO signaling pathway, the signaling molecules involved in the modulation of the intracellular redox environment, which plays an essential role in the biogenesis and biological function of mitochondria. Previous studies demonstrated that feeding NCG enhanced the antioxidant capacity of the liver, spleen and plasma in rats under oxidative stress [31,32]. The NCG increased plasma arginine concentration by activating carbamylphosphate synthase- 1 and pyr-roline5-carboxylate synthase, which were the key enzymes of endogenous arginine synthesis [20]. The ileal digestibility of most amino acids by supplementation of NCG is attributed to the increased endogenous amino acids synthesis [20]. The Leu can improve intestinal development and immune function by many physiological and metabolic functions [33]. A further experiment may be warranted to explore the impact of NCG on rumen function and intestinal health of beef cattle. 


\subsection{Slaughter Performance and Meat Quality}

NCG has been reported to improve muscle protein synthesis of pigs by inducing the endogenous synthesis of the Arg and the Arg family of AA and the phosphorylation of mTOR [34]. The greater dressing percentage of carcasses from bulls fed NCG compared to no-supplementation of NCG with a similar slaughter weight indicated that NCG regulates bulls to consume more resources to support gain in carcass weight. Feeding NCG are capable of benefiting organ development of broiler chickens [22]. However, NCG supplementation did not influence the organ index in the current results. Presumably, feeding NCG might interact with different breeds, development stages and length of feeding time.

Improved $\mathrm{N}$ and amino acid metabolism can contribute to advancements in the efficient and economical production of high-quality beef. One plausible explanation for in-creased eye muscle area by NCG supplementation was possibly related to the higher Arg and Leu concentrations. Arg and Leu played an important role in muscle protein synthesis by inducing the phosphorylation of mTOR [34,35]. Feeding growing pigs with $0.1 \%$ NCG improved longissimus dorsi muscle by enhancing the endogenous synthesis of the Arg and the amino acids in the Arg family [20]. In addition, the greater ileal digestibility of most amino acids in a low-protein diet supplemented with NCG is attributed to the enhanced endogenous AA synthesis and muscle protein accretion in pigs [20]. Water holding capacity indicates processing and sensory qualities in meat characteristics, and economic losses have been caused by lower water holding capacity [36]. Drip loss can be a good indicator of water holding capacity. In agreement with our results, reduced drip loss was observed in broilers with an amniotic injection of NCG [37]. A previous study also found that reduction of drip loss was associated with declined MDA level in porcine longissimus dorsi by supplementation of NCG [37]. The reduction of cooking loss was contributed to protein solubility, primarily collagen [38]. The improvements in shear forces are attributed to the decreased collagen content and solubility in the muscle. Meat color acts as a vital indicator deciding meat quality and acceptability. The meat color would be darker because there is less free water to reflect light when proteins bind water more strongly [39]. In according to our results, previous study also suggested that the increase in lightness may be responsible for a decrease in drip loss, and reduced water holding capacity may lead to greater shear force [40].

\section{Conclusions}

Supplementing diets of NCG enhanced growth performance through improving ADG, FCR, DM and CP digestibility. Concurrently, adding NCG in urea diets decreased contents of fecal and urinary $\mathrm{N}$ and plasma ammonia, which in turn improved nitrogen metabolism. On the other hand, feeding NCG improved meat quality by increasing eye muscle area, shear force and $\mathrm{L}^{*}$ of color, and decreased drip and cooking loss. Overall, beef benefited from being fed a NCG product in the control and urea diet. NCG is a promising feed additive in beef production.

Author Contributions: Q.Z.: data analysis, visualization, and writing—original draft; G.Z.: sample collection, formal analysis and data curation; X.Z., J.Y.: sample collection; Y.Z.: Investigation, conceptualization, funding acquisition, writing-review and editing. All authors have read and agreed to the published version of the manuscript.

Funding: This research was funded by China Agriculture Research System of MOF and MARA.

Informed Consent Statement: Informed consent was obtained from all subjects involved in the study.

Data Availability Statement: No new data were created or analyzed in this study. Data sharing is not applicable to this article.

Acknowledgments: The authors acknowledge the staff of Acheng Test Base for their assistance in feeding and sample collection. The authors also acknowledge the experimental support provided by Northeast Agricultural University. This study is supported by China Agriculture Research System of MOF and MARA. 
Conflicts of Interest: The authors have declared that they have no competing interests.

\section{References}

1. Morris, S.M., Jr. Recent advances in arginine metabolism: Roles and regulation of the arginases. Br. J. Pharmacol. 2009, 157, 922-930. [CrossRef]

2. $\quad$ Liu, Y.; Huang, J.; Hou, Y.; Zhu, H.; Zhao, S.; Ding, B.; Yin, Y.; Yi, G.; Shi, J.; Fan, W. Dietary arginine supplementation alleviates intestinal mucosal disruption induced by Escherichia coli lipopolysaccharide in weaned pigs. Br. J. Nutr. 2008, 100, 552-560. [CrossRef]

3. Xiao, L.; Cao, W.; Liu, G.; Fang, T.; Wu, X.; Jia, G.; Chen, X.; Zhao, H.; Wang, J.; Wu, C.; et al. Arginine, N-carbamylglutamate, and glutamine exert protective effects against oxidative stress in rat intestine. Anim. Nutr. 2016, 2, 242-248. [CrossRef]

4. Chacher, B.; Wang, D.-M.; Liu, H.-Y.; Liu, J.-X. Degradation of L-arginine and N-carbamoyl glutamate and their effect on rumen fermentationin vitro. Ital. J. Anim. Sci. 2012, 11, e68. [CrossRef]

5. Vivanti, A.; Ash, S.; Hulcombe, J.E. Validation of a satisfaction survey for rural and urban outpatient dietetic services. J. Hum. Nutr. Diet. 2007, 20, 41-49. [CrossRef]

6. Chacher, B.; Zhu, W.; Ye, J.; Wang, D.; Liu, J. Effect of dietary N-carbamoylglutamate on milk production and nitrogen utilization in high-yielding dairy cows. J. Dairy Sci. 2014, 97, 2338-2345. [CrossRef] [PubMed]

7. Wu, X.; Ruan, Z.; Gao, Y.; Yin, Y.; Zhou, X.; Wang, L.; Geng, M.; Hou, Y.; Wu, G. Dietary supplementation with 1-arginine or $\mathrm{N}$-carbamylglutamate enhances intestinal growth and heat shock protein-70 expression in weanling pigs fed a corn- and soybean meal-based diet. Amino Acids 2010, 39, 831-839. [CrossRef]

8. Zhang, H.; Sun, H.; Peng, A.; Guo, S.; Wang, M.; Loor, J.; Wang, H. N-carbamylglutamate and l-arginine promote intestinal function in suckling lambs with intrauterine growth restriction by regulating antioxidant capacity via a nitric oxide-dependent pathway. Food Funct. 2019, 10, 6374-6384. [CrossRef]

9. Zhang, H.; Peng, A.; Guo, S.; Wang, M.; Loor, J.; Wang, H. Dietary N-carbamylglutamate and l-arginine supplementation improves intestinal energy status in intrauterine-growth-retarded suckling lambs. Food Funct. 2019, 10, 1903-1914. [CrossRef]

10. Leonardi, C.; Stevenson, M.; Armentano, L. Effect of Two Levels of Crude Protein and Methionine Supplementation on Performance of Dairy Cows. J. Dairy Sci. 2003, 86, 4033-4042. [CrossRef]

11. Valadares, R.; Broderick, G.; Filho, S.V.; Clayton, M. Effect of Replacing Alfalfa Silage with High Moisture Corn on Ruminal Protein Synthesis Estimated from Excretion of Total Purine Derivatives. J. Dairy Sci. 1999, 82, 2686-2696. [CrossRef]

12. Gehman, A.; Kononoff, P.; Mullins, C.; Janicek, B. Evaluation of Nitrogen Utilization and the Effects of Monensin in Dairy Cows Fed Brown Midrib Corn Silage. J. Dairy Sci. 2008, 91, 288-300. [CrossRef] [PubMed]

13. Shingfield, K.; Offer, N. Simultaneous determination of purine metabolites, creatinine and pseudouridine in ruminant urine by reversed-phase high-performance liquid chromatography. J. Chromatogr. B Biomed. Sci. Appl. 1999, 723, 81-94. [CrossRef]

14. AOAC (Ed.) Official Methods of Analysis, 17th ed.; Association of Official Analytical Chemists: Arlington, VA, USA, 2000. Available online: https://www.nhbs.com/official-methods-of-analysis-of-aoac-international-17th-edition-book (accessed on 1 December 2021).

15. Van Soest, P.J.; Robertson, J.B.; Lewis, B.A. Methods for Dietary Fiber, Neutral Detergent Fiber, and Nonstarch Polysaccharides in Relation to Animal Nutrition. J. Dairy Sci. 1991, 74, 3583-3597. [CrossRef]

16. Lee, C.; Hristov, A. Short communication: Evaluation of acid-insoluble ash and indigestible neutral detergent fiber as total-tract digestibility markers in dairy cows fed corn silage-based diets. J. Dairy Sci. 2013, 96, 5295-5299. [CrossRef]

17. Tosta, M.R.; Prates, L.L.; Christensen, D.A.; Yu, P. Effects of processing methods (rolling vs pelleting vs. steam-flaking) of cool-season adapted oats on dairy cattle production performance and metabolic characteristics compared with barley. J. Dairy Sci. 2019, 102, 10916-10924. [CrossRef]

18. Ji, S.K.; Zhang, F.; Sun, Y.K.; Deng, K.D.; Wang, B.; Tu, Y.; Zhang, N.F.; Jiang, C.G.; Wang, S.Q.; Diao, Q.Y. Influence of dietary slow-release urea on growth performance, organ development and serum biochemical parameters of mutton sheep. J. Anim. Physiol. Anim. Nutr. 2016, 101, 964-973. [CrossRef]

19. Broderick, G.; Muck, R. Effect of alfalfa silage storage structure and rumen-protected methionine on production in lactating dairy cows. J. Dairy Sci. 2009, 92, 1281-1289. [CrossRef]

20. Ye, C.; Zeng, X.; Zhu, J.; Liu, Y.; Ye, Q.; Qiao, S.; Zeng, X. Dietary N-Carbamylglutamate Supplementation in a Reduced Protein Diet Affects Carcass Traits and the Profile of Muscle Amino Acids and Fatty Acids in Finishing Pigs. J. Agric. Food Chem. 2017, 65, 5751-5758. [CrossRef]

21. Yang, J.; Zheng, J.; Fang, X.; Jiang, X.; Sun, Y.; Zhang, Y. Effects of Dietary N-carbamylglutamate on Growth Performance, Apparent Digestibility, Nitrogen Metabolism and Plasma Metabolites of Fattening Holstein Bulls. Animals 2021, 11, 126. [CrossRef]

22. Hu, Y.; Shao, D.; Wang, Q.; Xiao, Y.; Zhao, X.; Shen, Y.; Zhang, S.; Tong, H.; Shi, S. Effects of dietary N-carbamylglutamate supplementation on growth performance, tissue development and blood parameters of yellow-feather broilers. Poult. Sci. 2019, 98, 2241-2249. [CrossRef] [PubMed]

23. Ebrahimi, M.; Shahneh, A.Z.; Shivazad, M.; Pirsaraei, Z.A.; Tebianian, M.; Ruiz-Feria, C.A.; Adibmoradi, M.; Nourijelyani, K.; Mohamadnejad, F. The effect of feeding excess arginine on lipogenic gene expression and growth performance in broilers. Br. Poult. Sci. 2014, 55, 81-88. [CrossRef] 
24. Wang, Y.; Han, S.; Zhou, J.; Li, P.; Wang, G.; Yu, H.; Cai, S.; Zeng, X.; Johnston, L.J.; Levesque, C.L.; et al. Effects of dietary crude protein level and $\mathrm{N}$-carbamylglutamate supplementation on nutrient digestibility and digestive enzyme activity of jejunum in growing pigs. J. Anim. Sci. 2020, 98, 88. [CrossRef] [PubMed]

25. Kim, S.W.; McPherson, R.L.; Wu, G. Dietary Arginine Supplementation Enhances the Growth of Milk-Fed Young Pigs. J. Nutr. 2004, 134, 625-630. [CrossRef]

26. Barbul, A. Arginine: Biochemistry, Physiology, and Therapeutic Implications. J. Parenter. Enter. Nutr. 1986, 10, 227-238. [CrossRef] [PubMed]

27. Yang, H.S.; Fu, D.Z.; Kong, X.F.; Wang, W.C.; Yang, X.J.; Nyachoti, C.M.; Yin, Y.L. Dietary supplementation with Ncarbamylglutamate increases the expression of intestinal amino acid transporters in weaned Huanjiang mini-pig piglets1. J. Anim. Sci. 2013, 91, 2740-2748. [CrossRef]

28. Wang, S.; Azarfar, A.; Wang, Y.; Cao, Z.; Li, S. N-carbamylglutamate restores nitric oxide synthesis and attenuates high altitudeinduced pulmonary hypertension in Holstein heifers ascended to high altitude. J. Anim. Sci. Biotechnol. 2018, 9, 63. [CrossRef]

29. Jobgen, W.S.; Fried, S.K.; Fu, W.J.; Meininger, C.; Wu, G. Regulatory role for the arginine-nitric oxide pathway in metabolism of energy substrates. J. Nutr. Biochem. 2006, 17, 571-588. [CrossRef]

30. Zhang, H.; Peng, A.; Yu, Y.; Guo, S.; Wang, M.; Wang, H. l-Arginine Protects Ovine Intestinal Epithelial Cells from Lipopolysaccharide-Induced Apoptosis through Alleviating Oxidative Stress. J. Agric. Food Chem. 2019, 67, 1683-1690. [CrossRef]

31. Cao, W.; Xiao, L.; Liu, G.; Fang, T.; Wu, X.; Jia, G.; Zhao, H.; Chen, X.; Wu, C.; Cai, J.; et al. Dietary arginine and Ncarbamylglutamate supplementation enhances the antioxidant statuses of the liver and plasma against oxidative stress in rats. Food Funct. 2016, 7, 2303-2311. [CrossRef]

32. Mo, W.; Wu, X.; Jia, G.; Zhao, H.; Chen, X.; Tang, J.; Wu, C.; Cai, J.; Tian, G.; Wang, J.; et al. Roles of dietary supplementation with arginine or N-carbamylglutamate in modulating the inflammation, antioxidant property, and mRNA expression of antioxidantrelative signaling molecules in the spleen of rats under oxidative stress. Anim. Nutr. 2018, 4, 322-328. [CrossRef] [PubMed]

33. Nakamura, I. Impairment of innate immune responses in cirrhotic patients and treatment by branched-chain amino acids. World J. Gastroenterol. 2014, 20, 7298-7305. [CrossRef] [PubMed]

34. Yao, K.; Yin, Y.L.; Chu, W.; Liu, Z.; Deng, D.; Li, T.; Huang, R.; Zhang, J.; Tan, B.; Wang, W.; et al. Dietary arginine supplementation increases mTOR signaling activity in skeletal muscle of neonatal pigs. J. Nutr. 2008, 138, 867-872. [CrossRef]

35. Suryawan, A.; Jeyapalan, A.S.; Orellana, R.A.; Wilson, F.A.; Nguyen, H.V.; Davis, T.A. Leucine stimulates protein synthesis in skeletal muscle of neonatal pigs by enhancing mTORC1 activation. Am. J. Physiol. Metab. 2008, 295, E868-E875. [CrossRef] [PubMed]

36. Schäfer, A.; Rosenvold, K.; Purslow, P.P.; Andersen, H.J.; Henckel, P. Physiological and structural events post mortem of importance for drip loss in pork. Meat Sci. 2002, 61, 355-366. [CrossRef]

37. Zhang, F.-D.; Wang, J.; Zhang, H.-J.; Wu, S.-G.; Lin, J.; Qi, G.-H. Effect of Amniotic Injection of N-Carbamylglutamate on Meat Quality of Broilers. Animals 2020, 10, 576. [CrossRef]

38. Tůmová, E.; Chodová, D.; Volek, Z.; Ketta, M. The effect of feed restriction, sex and age on the carcass composition and meat quality of nutrias (Myocastor coypus). Meat Sci. 2021, 182, 108625. [CrossRef]

39. Page, J.K.; Wulf, D.M.; Schwotzer, T.R. A survey of beef muscle color and pH. J. Anim. Sci. 2001, 79, 678-687. [CrossRef]

40. Geesink, G.H.; Smulders, F.; Van Laack, H.; Van Der Kolk, J.H.; Wensing, T.; Breukink, H.J. Effects on meat quality of the use of clenbuterol in veal calves. J. Anim. Sci. 1993, 71, 1161-1170. [CrossRef] [PubMed] 